\title{
Role of Inflammatory Markers in the Differential Diagnosis of Bleeding in Early Pregnancy
}

\author{
Nehad M. Hosni*, Iman A. Ahmedy, Ayman Elsayed Solyman \\ Department of Obstetrics and Gynecology, Faculty of Medicine, Menoufia University, Menoufia, Egypt \\ *Corresponding author: Nehad M. Hosni, Mobile: (+20)01063035400, Email: nehadm. hosni@ gmail.com
}

\begin{abstract}
Background: Defective placentation as a cause of many pregnancy-related conditions including abortion and ectopic pregnancy will involve abnormal inflammatory response. Assessment of different inflammatory markers as neutrophillymphocyte ratio (NLR), platelet-lymphocyte ratio (PLR), and lymphocyte-monocyte ratio (LMR) may aid in the differentiation of causes of bleeding in early pregnancy.

Objective: To verify the ability of NLR, PLR, and LMR to differentiate cases of miscarriage or ectopic pregnancy from normal pregnancy in patients presenting with bleeding in the first trimester.

Patients and Method: A prospective observational study of 150 patients presenting with bleeding in the first trimester were enrolled in the study. After history taking, clinical examination, ultrasound, quantitative beta-human chorionic gonadotropin (B-hCG), or laparoscopy, patients were allocated into three groups: miscarriage group (60 patients), ectopic pregnancy group (30 patients), and control group (60 patients) who continued their pregnancy beyond 20 weeks. For all patients NLR, PLR, and LMR were calculated.

Results: NLR was significantly higher and LMR was significantly lower in ectopic pregnancy group when compared to the miscarriage group or the normal pregnancy group. A cutoff level of $>2.7$ for NLR and $<3.7$ for LMR has a sensitivity of $80 \%$ and $70 \%$, and a specificity of $60 \%$ and $80 \%$, respectively.

Conclusion: Utilization of both NLR and LMR will aid in the differentiation of cases of ectopic pregnancy from normal pregnancy or miscarriage with an acceptable sensitivity and specificity.
\end{abstract}

Keywords: Ectopic, Inflammatory markers, LMR, Miscarriage, NLR.

\section{INTRODUCTION}

Implantation which is a flawless dialogue between the blastocyst and endometrium/decidua involves a local inflammatory response that allows cell clearance, cell growth, angiogenesis, and tolerance ${ }^{(\mathbf{1})}$. Disruption of this process will result in defective placentation which is responsible for many pregnancy-related conditions ${ }^{(2,3)}$.

It entails abnormal inflammatory response, hence, the idea of employing different inflammatory markers as prognostic and/or diagnostic indicators.

Bleeding in early pregnancy is one of such conditions that is relatively common. Approximately one fourth of pregnant women will experience bleeding in the first trimester ${ }^{(4)}$. It does not always mean there is a problem. However, it may signal grave complications as miscarriage and ectopic pregnancy. Miscarriage affects woman not only physically but psychologically as well. The American College of Obstetricians and Gynecologists (ACOG) estimated that as many as $26 \%$ of all pregnancies end in miscarriage ${ }^{(5)}$.

The frequency of clinically recognized early pregnancy loss for women aged 20-30 years is $9-17 \%$, and this rate increases sharply from $20 \%$ at the age of 35 years to $40 \%$ at the age of 40 years ${ }^{\left({ }^{(}\right)}$. Approximately $80 \%$ of all cases of pregnancy loss occur within the first trimester ${ }^{(7)}$.

On the other hand, ectopic pregnancy is a major health problem that may cause serious morbidity and mortality in young women. The world-wide prevalence of ectopic pregnancy is around $1-2 \%$ per number of pregnancies ${ }^{(8)}$. UK Confidential Enquiry into Maternal and Child Health (CEMACH) reported a maternal mortality rate due to ectopic pregnancy of 0.3 per 100000 maternities ${ }^{(9)}$.

Despite the great advances in ultrasound machines and the administration of sensitive assay of B-subunit of human chorionic gonadotrophins (B-hCG), the differentiation between intrauterine pregnancy and ectopic pregnancy remains problematic in some cases. CBC which is a simple and routine investigation in such cases may be utilized to give a clue for the diagnosis. NLR, PLR, and LMR have been proposed to differentiate between causes of bleeding in the first trimester ${ }^{(15)}$.

The aim of this study is to verify the ability of NLR, PLR, and LMR to differentiate cases of miscarriage or ectopic pregnancy from normal pregnancy in patients presenting with bleeding in the first trimester.

\section{PATIENTS AND METHOD}

A prospective observational study was conducted at the Obstetrics and Gynecology Department, Menoufia University Hospital from March 2020 to September 2021 including 150 patients who were presenting by bleeding in early pregnancy. 


\section{Ethical considerations:}

The study was approved by the Ethical Committee of Faculty of Medicine, Menoufia University and all patients signed an informed consent. This work has been carried out in accordance with The Code of Ethics of the World Medical Association (Declaration of Helsinki) for studies involving humans.

Initially, 212 patients were recruited for the study with the following specifications: pregnant 6-13 weeks, singleton pregnancy, with bleeding in the first trimester. Exclusion criteria included: vesicular mole, medical disorders, chronic inflammatory or autoimmune conditions as rheumatoid arthritis and psoriasis, acute infections, hyperemesis, recent intake of any antiinflammatory drugs, obese patients, smoking, and heterotopic pregnancy.

Accordingly, 62 patients were excluded and the remaining 150 were allocated into; control group included 60 patients who continued pregnancy beyond 20 weeks, missed abortion group (60 patients), and ectopic pregnancy group (30 patients) as confirmed by repeated quantitative B-subunit, ultrasound, and laparoscopy if indicated (Figure 1).

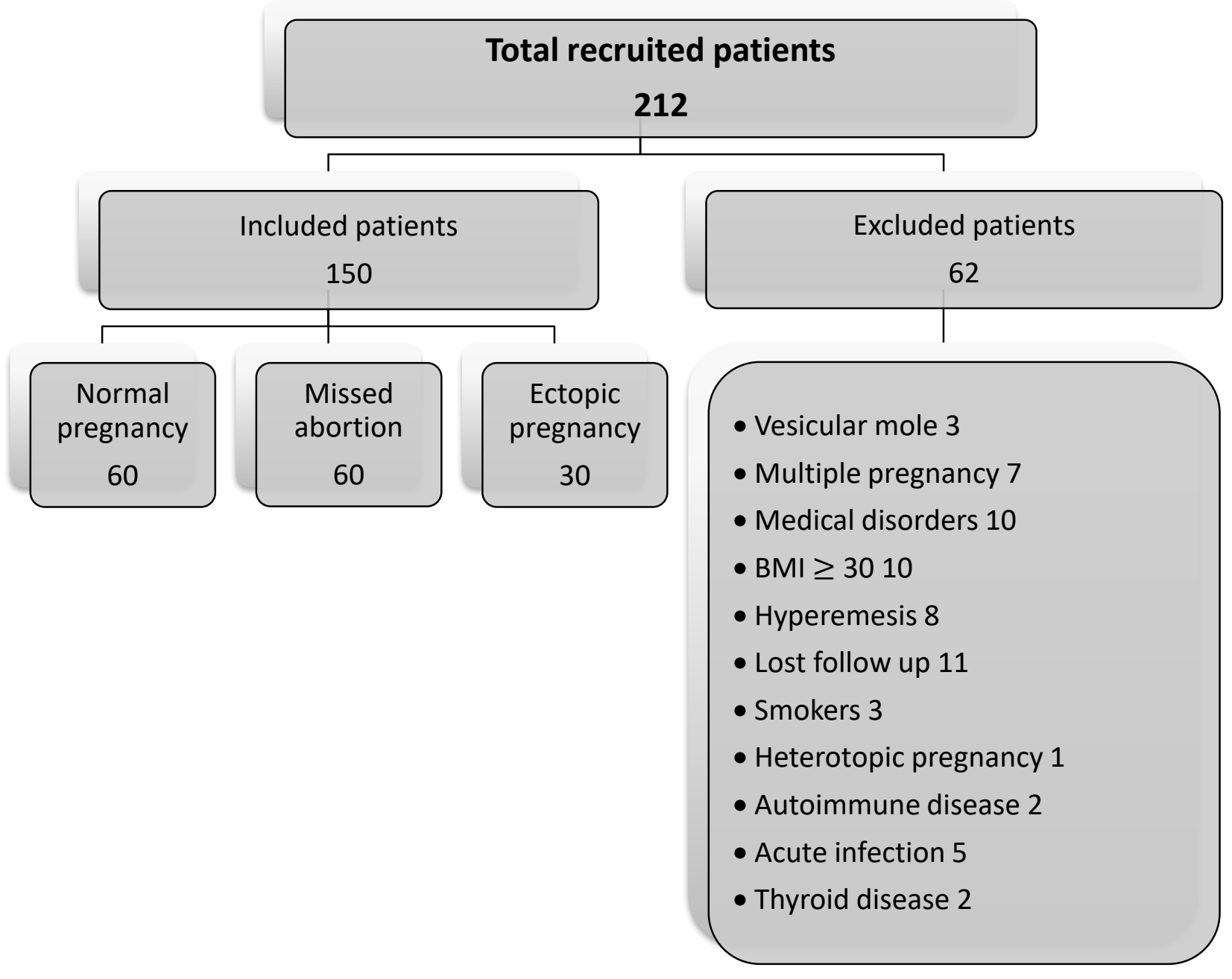

Figure (1): Flow chart of the participants. 
Thorough history taking, and clinical examination were performed. Pelvic ultrasound using 2D grayscale ultrasound system (IBE sonata plus) via abdominal and/or transvaginal probe (3-5 MHZ) were done to confirm location of pregnancy, fetal life, and gestational age. Venous samples for complete blood picture $(\mathrm{CBC})$ were collected on EDTA tubes from all patients before any surgical interference using automated Analyzer (Sysmex XN-1000 B.M Egypt Company, Japan (19723). Leishman-stained film was interpreted microscopically. Neutrophil-lymphocyte ratio (NLR), platelet -lymphocyte ratio (PLR), and lymphocyte-monocyte ratio (LMR) were then calculated.

\section{Statistical analysis}

Data were collected, tabulated, statistically analyzed using a personal computer with Statistical Package for the Social Sciences (SPSS) version 22 (SPSS Inc., Chicago, Illinois, USA). Two types of statistics were done: Descriptive statistics e.g., Number (No), percentage (\%), mean and Median and interquartile range (IQR). One-way Anova test was used for comparison between more than two groups having quantitative variables with independentparametric data. Kruskal-Wallis test was used for comparison between more than two groups having quantitative variables and with independent nonparametric data. Post Hoc test was used for multiple comparisons between groups if $\mathrm{P}$ after using ANOVA or Kruskal-Wallis test was significant. Receiver Operating Characteristics (ROC) curve was plotted to calculate the best cutoff point and other diagnostic tests. $P$ value $<0.05$ was considered significant.

\section{RESULTS}

There were no statistically significant differences between the study groups regarding parity, BMI, and number of previous miscarriages. However, there was significant difference between the normal pregnancy group and the ectopic pregnancy group regarding patient age. Also, there was statistically significant difference between the duration of pregnancy of ectopic pregnancy group (shorter) when compared to the normal pregnancy group or the abortion group (Table $1)$.

Table (1): Clinical data of the study groups

\begin{tabular}{|c|c|c|c|c|c|c|}
\hline Clinical data & $\begin{array}{c}\text { Normal } \\
\text { pregnancy } \\
\text { No }=60\end{array}$ & $\begin{array}{c}\text { Abortion } \\
\text { No }=60\end{array}$ & $\begin{array}{l}\text { Ectopic } \\
\text { No }=30\end{array}$ & $\begin{array}{l}\text { Test of } \\
\text { sig }\end{array}$ & $P$ value & Post hoc \\
\hline $\begin{array}{l}\text { Age (years) } \\
\text { Mean } \pm \text { SD } \\
\text { Median (IQR) }\end{array}$ & $\begin{array}{c}26.9 \pm 5.6 \\
25(22-31.5)\end{array}$ & $\begin{array}{c}28.7 \pm 5.8 \\
30(25-33.7)\end{array}$ & $\begin{array}{c}30 \pm 3.7 \\
30(28-33)\end{array}$ & $\begin{array}{l}\mathrm{F} \\
3.5\end{array}$ & $0.030 *$ & $\begin{array}{l}\mathrm{P} 1=0.070 \\
\mathrm{P} 2=0.012 * \\
\mathrm{P} 3=0.302\end{array}$ \\
\hline $\begin{array}{l}\text { BMI } \\
\text { Mean } \pm \text { SD } \\
\text { Median (IQR) }\end{array}$ & $\begin{array}{c}24.3 \pm 2.2 \\
24(23-26)\end{array}$ & $\begin{array}{c}25.7 \pm 2.5 \\
26(24-28)\end{array}$ & $\begin{array}{c}26.3 \pm 1.4 \\
26(25-27)\end{array}$ & $\begin{array}{c}F \\
0.603\end{array}$ & 0.548 & ------ \\
\hline $\begin{array}{l}\text { Parity } \\
\text { Mean } \pm \text { SD } \\
\text { Median (IQR) }\end{array}$ & $\begin{array}{c}1.4 \pm 1.3 \\
1(0-2)\end{array}$ & $\begin{array}{c}1.6 \pm 1.4 \\
1(0.25-2.7)\end{array}$ & $\begin{array}{l}1.7 \pm 1.2 \\
2(1-2)\end{array}$ & $\begin{array}{l}\mathrm{K} \\
1.9\end{array}$ & 0.383 & ----- \\
\hline $\begin{array}{l}\text { Number of previous } \\
\text { miscarriages } \\
\text { Mean } \pm \text { SD } \\
\text { Median (IQR) }\end{array}$ & $\begin{array}{c}0.50 \pm 0.87 \\
1(0-1)\end{array}$ & $\begin{array}{c}0.45 \pm 0.87 \\
1(0-0.75)\end{array}$ & $\begin{array}{c}0.40 \pm 0.67 \\
0.4(0-1)\end{array}$ & $\begin{array}{c}\mathrm{K} \\
0.266\end{array}$ & 0.875 & ------ \\
\hline $\begin{array}{l}\text { Duration of current } \\
\text { pregnancy (weeks) } \\
\text { Mean } \pm \mathrm{SD} \\
\text { Median (IQR) }\end{array}$ & $\begin{array}{c}9.9 \pm 1.8 \\
10(8.2-11.7)\end{array}$ & $\begin{array}{l}10.5 \pm 2.2 \\
11(8-13)\end{array}$ & $\begin{array}{l}6.9 \pm 1.1 \\
6.5(6-8) \\
\end{array}$ & $\begin{array}{c}\mathrm{F} \\
37.8\end{array}$ & $<0.001 *$ & $\begin{aligned} \mathrm{P} 1 & =0.066 \\
\mathrm{P} 2 & =<0.001 * \\
\mathrm{P} 3 & =<0.001 *\end{aligned}$ \\
\hline
\end{tabular}

$\mathrm{F}=\mathrm{ANOVA}$ test, $\mathrm{K}=$ Kruskal Wallis test, *significant

$\mathrm{P} 1=$ normal pregnancy vs Abortion, $\mathrm{P} 2=$ normal pregnancy vs Ectopic, $\mathrm{P} 3=$ Abortion vs Ectopic

The total leukocytic count and the number of neutrophil and monocytes were significantly higher in ectopic pregnancy group in comparison to normal pregnancy or abortion group. The platelet number significantly differs in the abortion group when compared to the normal pregnancy or ectopic pregnancy group. Lymphocytes did not show significant difference between the three groups (Table 2).

There were 5 patients out of thirty of the ectopic pregnancy group had ruptured ectopic and one was chronically disturbed. PLR showed no significant difference between the three study groups. On the other hand, NLR was significantly higher (mean 4.1, range 1.4-7.5) and LMR was significantly lower (mean 3.9, range 2.4-6.8) in the ectopic pregnancy group compared to the normal pregnancy or the abortion group. This was particularly evident in the ruptured ectopic pregnancy patients (6 patients) as the highest NLR (7.5) and the lowest LMR (2.4) were observed in such patients (Table 2). 
Table (2): Total and differential leucocytic count, PLR, NLR, and LMR of the study groups

\begin{tabular}{|c|c|c|c|c|c|c|}
\hline & $\begin{array}{c}\text { Normal } \\
\text { pregnancy } \\
\text { No }=60\end{array}$ & $\begin{array}{c}\text { Abortion } \\
\text { No }=60\end{array}$ & $\begin{array}{c}\text { Ectopic } \\
\text { No }=30\end{array}$ & $\begin{array}{l}\text { Test } \\
\text { of sig }\end{array}$ & $P$ value & Post hoc \\
\hline $\begin{array}{l}\text { TLC }\left(\mathbf{1 0}^{\mathbf{3}} / \boldsymbol{\mu L}\right) \\
\text { Mean } \pm \text { SD } \\
\text { Median (IQR) }\end{array}$ & $\begin{array}{c}6.83 \pm 1.33 \\
6.95(5.70-8.16)\end{array}$ & $\begin{array}{c}7.44 \pm 1.48 \\
7.70(6.20-8.68)\end{array}$ & $\begin{array}{c}10.09 \pm 3.19 \\
9.75(8.60-11.40)\end{array}$ & $\begin{array}{c}\mathrm{F} \\
30.6\end{array}$ & $<0.001^{*}$ & $\begin{aligned} \mathrm{P} 1 & =0.083 \\
\mathrm{P} 2 & =<0.001^{*} \\
\mathrm{P} 3 & =<0.001^{*}\end{aligned}$ \\
\hline $\begin{array}{l}\text { Neutrophils } \\
\left(\mathbf{1 0}^{\mathbf{3}} / \boldsymbol{\mu} \boldsymbol{L}\right) \\
\text { Mean } \pm \text { SD } \\
\text { Median (IQR) }\end{array}$ & $\begin{array}{c}4.94 \pm 1.59 \\
4.66(3.80-6.50)\end{array}$ & $\begin{array}{c}4.89 \pm 1.58 \\
4.75(3.33-6.40)\end{array}$ & $\begin{array}{c}7.38 \pm 3.22 \\
7.95(4.60-8.50)\end{array}$ & $\begin{array}{c}\mathrm{F} \\
18.1\end{array}$ & $<0.001^{*}$ & $\begin{array}{c}\mathrm{P} 1=0.888 \\
\mathrm{P} 2=<0.001 * \\
\mathrm{P} 3=<0.001 *\end{array}$ \\
\hline $\begin{array}{l}\text { Lymphocytes } \\
\left(\mathbf{1 0}^{\mathbf{3}} / \boldsymbol{\mu} \boldsymbol{L}\right) \\
\text { Mean } \pm \text { SD } \\
\text { Median (IQR) }\end{array}$ & $\begin{array}{c}2.11 \pm 0.523 \\
2(1.72-2.58)\end{array}$ & $\begin{array}{c}2.08 \pm 0.514 \\
1.90(1.73-2.28)\end{array}$ & $\begin{array}{c}1.98 \pm 0.670 \\
1.90(1.40-2.20)\end{array}$ & 2.4 & 0.301 & ----- \\
\hline $\begin{array}{l}\text { Monocytes } \\
\left(\mathbf{1 0}^{3} / \boldsymbol{\mu} \boldsymbol{L}\right) \\
\text { Mean } \pm \text { SD } \\
\text { Median (IQR) } \\
\end{array}$ & $\begin{array}{c}0.382 \pm 0.118 \\
0.40(0.30-0.50)\end{array}$ & $\begin{array}{c}0.385 \pm 0.092 \\
0.40(0.30-0.40)\end{array}$ & $\begin{array}{c}0.527 \pm 0.104 \\
0.50(0.50-0.60) \\
\end{array}$ & $\begin{array}{c}\mathrm{F} \\
22.2\end{array}$ & $<0.001^{*}$ & $\begin{array}{c}\mathrm{P} 1=0.877 \\
\mathrm{P} 2=<0.001^{*} \\
\mathrm{P} 3=<0.001^{*}\end{array}$ \\
\hline $\begin{array}{l}\text { Platelets } \\
\left(\mathbf{1 0}^{\mathbf{3}} / \boldsymbol{\mu} \boldsymbol{L}\right) \\
\text { Mean } \pm \text { SD } \\
\text { Median (IQR) }\end{array}$ & $\begin{array}{c}271.35 \pm 61.97 \\
268(228.75-327)\end{array}$ & $\begin{array}{c}245.90 \pm 61.38 \\
246.50(221-286)\end{array}$ & $\begin{array}{l}277.30 \pm 47.46 \\
295(235-306)\end{array}$ & $\begin{array}{l}\mathrm{K} \\
6.1\end{array}$ & $0.049 *$ & $\begin{array}{l}\mathrm{P} 1=0.020^{*} \\
\mathrm{P} 2=0.653 \\
\mathrm{P} 3=0.019^{*}\end{array}$ \\
\hline $\begin{array}{l}\text { PLR } \\
\text { Mean } \pm \text { SD } \\
\text { Median (IQR) }\end{array}$ & $\begin{array}{c}135.1 \pm 41.3 \\
128(104-153.2)\end{array}$ & $\begin{array}{c}125.5 \pm 40.6 \\
127.8(108-148.9)\end{array}$ & $\begin{array}{c}146.5 \pm 40.7 \\
148.5(128-175)\end{array}$ & $\begin{array}{c}F \\
2.68\end{array}$ & 0.072 & ------ \\
\hline $\begin{array}{l}\text { NLR } \\
\text { Mean } \pm \text { SD } \\
\text { Median (IQR) }\end{array}$ & $\begin{array}{c}2.4 \pm 0.85 \\
2.25(2-2.70)\end{array}$ & $\begin{array}{c}2.5 \pm 1.2 \\
2.22(1.3-3.5)\end{array}$ & $\begin{array}{c}4.1 \pm 1.8 \\
3.5(3-5.1)\end{array}$ & $\begin{array}{c}\mathrm{K} \\
20.2 \\
\end{array}$ & $<0.001^{*}$ & $\begin{aligned} \mathrm{P} 1 & =0.528 \\
\mathrm{P} 2 & =<0.001^{*} \\
\mathrm{P} 3 & =<0.001^{*}\end{aligned}$ \\
\hline $\begin{array}{l}\text { LMR } \\
\text { Mean } \pm \text { SD } \\
\text { Median (IQR) }\end{array}$ & $\begin{array}{c}5.8 \pm 1.4 \\
5.6(5-6.4)\end{array}$ & $\begin{array}{c}5.7 \pm 1.7 \\
6.1(3.9-7.1)\end{array}$ & $\begin{array}{c}3.9 \pm 1.3 \\
3.6(2.9-4.7)\end{array}$ & $\begin{array}{c}F \\
15.9\end{array}$ & $<0.001 *$ & $\begin{aligned} \mathrm{P} 1 & =0.650 \\
\mathrm{P} 2 & =<0.001^{*} \\
\mathrm{P} 3 & =<0.001^{*}\end{aligned}$ \\
\hline
\end{tabular}

$\mathrm{F}=$ ANOVA test. $\mathrm{K}=$ Kruskal Wallis test. *significant

A cutoff level of $>2.7$ for NLR had a sensitivity of $80 \%$, specificity of $60 \%$, negative predictive value (NPV) of $86 \%$, positive predictive value (PPV) of $52 \%$, and accuracy of $69 \%$ for diagnosis of ectopic pregnancy (Table 3 ). Meanwhile, a cutoff value of $<3.7$ for LMR had a sensitivity of $70 \%$, specificity of $80 \%$, NPV of $84 \%$, PPV of $64 \%$, and accuracy of $77 \%$ (Table 4).

Table (3): NLR as a predictor for ectopic pregnancy

\begin{tabular}{|l|l|l|l|l|l|l|l|}
\hline AUC & Sig. & cutoff & Sensitivity & Specificity & NPV & PPV & Accuracy \\
\hline 0.725 & 0.001 & $>2.70$ & $80 \%$ & $60 \%$ & $86 \%$ & $52 \%$ & $69 \%$ \\
\hline
\end{tabular}

Table (4): LMR as a predictor for ectopic pregnancy

\begin{tabular}{|c|r|l|r|r|r|r|r|}
\hline AUC & Sig. & cutoff & Sensitivity & Specificity & NPV & PPV & Accuracy \\
\hline 0.778 & 0.001 & $<3.7$ & $70 \%$ & $80 \%$ & $84 \%$ & $64 \%$ & $77 \%$ \\
\hline
\end{tabular}

\section{DISCUSSION}

Immunology of pregnancy is a distinctive, highly controlled system that permits continuation of healthy pregnancy till term. Immune system is not suppressed during pregnancy but instead, is modulated (10). Leukocytes as a principal component of the immune system have a chief role in promoting successful pregnancy. They may, however, be involved in the pathophysiology of different pregnancy disorders involving decidua and placenta ${ }^{(11)}$. Being divisions of the leukocytic count, neutrophils, lymphocytes, and monocytes can participate in the diagnosis of such conditions. In the present study, different inflammatory parameters of complete blood count (CBC) as neutrophil-lymphocyte ratio (NLR), plateletlymphocyte ratio (PLR), and lymphocyte-monocyte ratio (LMR) were tested for differentiating miscarriage and ectopic pregnancy from normal pregnancy in patients with bleeding in early pregnancy.

In the current study, NLR and LMR showed statistically significant difference in patients with ectopic pregnancy when compared to patients with 
normal pregnancy or patients with missed abortion. Conversely, PLR showed no significant difference between different groups of the study. Feng et al. ${ }^{(12)}$ found no significant difference in the pregnancy outcome for PLR and NLR although higher LMR was related to a lower risk of miscarriage in women with early threatened abortion.

Our study showed that NLR was significantly higher (4.1), while LMR was significantly lower (3.9) in ectopic pregnancy group compared to the other two groups. A cutoff value of $>2.7$ for NLR revealed sensitivity of $80 \%$ and specificity of $60 \%$. Meanwhile, LMR cutoff value of $<3.7$ showed sensitivity of $70 \%$ and specificity of $80 \%$. Accordingly, using both parameters will ensure good sensitivity and specificity for diagnosing ectopic pregnancy.

Concomitantly, there were six patients with disturbed ectopic pregnancy who showed obviously increased NLR and decreased LMR. However, because their number was few, we can't confirm a conclusion. Similar finding has been approved by Kan et al. ${ }^{(13)}$ and Donmez et al. ${ }^{(14)}$ who reported that both NLR and PLR were significantly higher in ruptured tubal ectopic pregnancy compared to the non-ruptured group.

Likewise, Karakus et al. (15) reported significantly higher NLR of patients with ectopic pregnancy compared to NLR of patients of normal pregnancy or miscarriage. Moreover, they noticed that NLR of miscarriage group was higher than that of patients with normal pregnancy, but the difference wasn't statistically significant, which was congruent with our results. They also found NLR cutoff value of 3 has sensitivity and specificity of $61 \%$ for diagnosing ectopic pregnancy.

Comparably, our results were consistent with that of Gencdal et al. ${ }^{(16)}$ who found that the mean NLR was higher in ectopic pregnancy than control group $(\mathrm{P}<$ $0.05)$.

Conversely, the study of Kim ${ }^{(17)}$, revealed significantly lower NLR in patients with missed abortion when compared to patients with threatened abortion. However, Biyik et al. (18) reported significantly higher NLR in missed abortion group as compared to normal pregnancy group ( $\mathrm{P}$ 0.038). Meanwhile, Christoforaki et al. ${ }^{(19)}$ stated that NLR doesn't differ significantly between normal pregnancy group and miscarriage group but NLR value $>5.8$ were solely found in miscarriage group.

In conclusion, the present study showed that in ectopic pregnancy NLR will increase and LMR will decrease. Use of both ratios can help in the diagnosis of ectopic pregnancy particularly in patients with disturbed ectopic with an acceptable sensitivity and specificity.
Financial support and sponsorship: Nil.

\section{Conflict of interest: Nil.}

\section{REFERENCES}

1. Mor G, Aldo P, Alvero A (2017): The unique immunological and microbial aspects of pregnancy. Nature Review Immunology, 17: 469-482.

2. Pollheimer J, Vondra S, Baltayeva J et al. (2018): Regulation of placental extravillous trophoblast by the maternal uterine environment. Front Immunol., 9: 2597.

3. Romero R, Kusanovic J, Chaiworapongsa T (2011): Placental bed disorders in preterm labor, preterm PROM, spontaneous abortion, and abruptio placentae. Best Practice Res Clin Obstet Gynecol., 25 (3): 313-327.

4. Hendriks E, Macnaughton H, Mackenzie M (2019): First trimester bleeding: evaluation and management. Am Fam Physician, 99 (3): 166-174.

5. Dugas C, Slane V (2021): Miscarrige. StatPearls. https://www.ncbi.nlm.nih.gov/ books/NBK532992/

6. Committee on Practice Bulletins-Gynecology (2015): The American College of Obstetrician and Gynecologists Practice Bulletin no 150. Early pregnancy loss. Obstet Gynecol., 125(5): 1258- 1267

7. Wilcox A, Weinberg C, O'Connor J et al. (1988): Incidence of early loss of pregnancy. N Engl J Med., 319: 189-94

8. Salman G, Iruine L (2008): Ectopic pregnancy the need for standardization of rate. Journal of Obstetrics and Gynecology, 28(1): 32- 5.

9. Cantwell R, Clutton-Brock T, Cooper G et al. (2011): Saving mother's lives: reviewing maternal deaths to make motherhood safer 2006-2008. The $8^{\text {th }}$ report of the Confidential Enquiries into Maternal deaths in the United Kingdom. BJOG., 118: 1-203.

10. Orefice R (2021): Immunology and the immunological response in pregnancy. Best Practice and Research Clinical Obstetrics and Gynecology, 76: 3-12.

11. Laresgoiti-Servitje E (2013): A leading role of the immune system in the pathophysiology of preeclampsia. J Leukoc Biol., 94: 247-257.

12. Feng Q, Chen C, Yu Q et al. (2020): The benefits of higher LMR for early threatened abortion: A retrospective Cohort study. PloS One, 15 (4): 0231642. https://doi.org/_10.1371/Journal.pone

13. Kan O, Gemici A, Alkilic A et al. (2019): The effect of preoperative neutrophil to lymphocyte ratio and platelet to lymphocyte ratio on predicting rupture risk in tubal ectopic pregnancy. Gynecol Obstet Invest., 84 (4): 1-5.

14. Donmez E, Arinkan S, Sut H et al. (2018): Importance of inflammatory makers in predicating rupture in ectopic pregnancies EJMO., 2(4): 198- 202.

15. Karakus S, Yildiz C, Akkar O et al. (2016): The significance of the neutrophil to lymphocyte ratio in differential diagnosis of ectopic pregnancy and miscarriage. Int J Clin Exp Med., 9 (6): 11327-11333.

16. Gencdal S, Aydogmus H, Gencdal N et al. (2019): Evaluation of the neutrophil-lymphocyte and platelet lymphocyte ratio in patients with ectopic pregnancy. J Clin Gynecol Obstet., 8(3): 8184.

17. Kim Y (2020): Retrospective analysis of prognostic value of the neutrophil-to lymphocyte ratio in early miscarriage. An 8-year survey. Kim Medicine, 99: 27-31.

18. Biyik I, Albayrak M, Keskin F (2020): Platelet to lymphocyte ratio and neutrophil to lymphocyte ratio in missed abortion. Rev Bras Ginecol Obstet., 42 (5): 235-239.

19. Christoforaki V, Zafeiriou Z, Daskalakis G et al. (2019): First trimester neutrophil to lymphocyte ratio (NLR) and pregnancy outcome. J Obstet Gynecol., 40 (1): 59-46. 